e-Journal Pendidikan Sosiologi Universitas Pendidikan Ganesha

Jurusan Sejarah, Sosiologi dan Perpustakaan (Volume 2, Nomor 1, Tahun 2020)

\title{
Pemertahanan Desa Adat Berbasis Kontrol Sosial Terhadap Sumber Daya Tanah ( Studi Kasus di Desa Tista, Abang, Karangasem-Bali )
}

\author{
I Putu Gede Sriada, Nengah Bawa Atmadja, I Gusti Made Arya Suta Wirawan \\ Jurusan Pendidikan Sosiologi \\ Universitas Pendidikan Ganesha \\ Singaraja, Indonesia
}

Email: iputu.gede.sriada17@gmail.com, nengahbawaatmadja@yahoo.com, arthasuta@gmail.com

\begin{abstract}
Abstrak
Penelitian ini bertujuan untuk 1) Menjelaskan alasan Mengapa Desa Adat Tista, Kecamatan Abang, Kabupaten Karangasem-Bali melarang jual/beli tanah pada orang luar desa.2) Menganalisis pengelolaan sumber daya tanah di Desa Adat Tista, Kecamatan Abang, Kabupaten Karangasem-Bali.3) Menjelaskan Aspek-aspek yang bisa digunakan sebagai media pembelajaran sosiologi mengenai permasalahan tanah di Desa Adat Tista, Kecamatan Abang, Kabupaten Karangasem-Bali. Penelitian ini menggunakan metode kualitatif dan dengan tahaptahap; 1) Teknik penetuan lokasi penelitian, penelitian ini berlokasi di Desa Tista, Kecamatan Abang, Kabupaten Karangasem-Bali.2) Jenis dan sumber data, melalui data primer dengan teknik purposive sampling, Data Skunder.3) Teknik pengumpulan data, melalui teknik observasi, wawancara dan studi dokumen.4) Teknik keabsahan data dengan cara tirianggulasi dengan sumber, trianggulasi dengan metode dan trianggulasi dengan teori.5) Teknik analisis data dengan cara reduksi data, penyajian data, penarikan kesimpulan. Hasil penelitian menunjukkan bahwa, Desa Adat Tista, Kecamatan Abang, Kabupaten Karangasem-Bali melarang jual/beli tanah pada orang luar desa. Adapun faktor-faktor yang melatar belakangi hal tersebut ialah pemertahanan budaya/agama, kemajuan ekonomi masyarakat lokal, pemertahanan keajegan desa/identitas desa, Adapun Strategi Pengelolaan Sumber Daya Tanah Yang Dilakukan di Desa Adat Tista, Kecamatan Abang, Kabupaten Karangasem-Bali adalah dengan Penetapan ayaahan desa, patokan jumlah tanah yang boleh dibeli. Surat tanah menggunakan pemohon/atas nama Desa Tista. Kemudian kasus yang diangkat dalam penelitian ini memiliki kelayakan untuk dijadikan sebagai sumber belajar sosiologi pada jenjang SMA.
\end{abstract}

Kata Kunci: Fenomena, Kearifan Lokal, Identitas, Budaya. 
e-Journal Pendidikan Sosiologi Universitas Pendidikan Ganesha

Jurusan Sejarah, Sosiologi dan Perpustakaan (Volume 2, Nomor 1, Tahun 2020)

\begin{abstract}
This study aims to 1) Explain the reasons why Tista Adat Village, Abang District, Karangasem-Bali Regency prohibits selling / buying land to people outside the village.2) Analyzing the management of land resources in Adat Tista Village, Abang District, Karangasem Regency-Bali. 3) Explain aspects that can be used as sociology learning media about land issues in the Tista Customary Village, Abang District, Karangasem Regency-Bali. This study uses qualitative methods and with stages; 1) Determination of research location techniques, this study is located in Tista Village, Abang District, Karangasem Regency-Bali.2) Types and sources of data, through primary data with purposive sampling techniques, Secondary Data.3) Data collection techniques, through observation techniques, interviews and document studies. 4) Data validity techniques by tirianggulasi with sources, triangulation by methods and triangulation with theories. 5) Data analysis techniques by data reduction, data presentation, drawing conclusions. The results showed that, Adat Tista Village, Abang District, Karangasem-Bali Regency prohibited the sale / purchase of land to people outside the village. The factors behind this are cultural / religious retention, economic progress of the local community, retention of village identity / village identity, The Land Resource Management Strategy undertaken in Adat Tista Village, Abang District, Karangasem Regency-Bali is by Determination village father, benchmark the amount of land that can be purchased. Land certificate using the applicant / on behalf of Tista Village. Then the case raised in this study has the feasibility to be used as a source of learning sociology at the high school level.
\end{abstract}

Keywords: Phenomenon, Local Wisdom, Identity, Culture.

\section{PENDAHULUAN}

Hubungan antara manusia dengan tanah sangatlah erat yang biasa dianggap sebagai pertalian hukum antara umat manusia dengan tanah. Melihat dari hal tersebut maka antara kelompok orang dengan tanah memiliki hubungan yang sangat erat sehingga sekelompok orang memiliki hak untuk menguasai tanah dalam hal ini berarti memanfaatkan tanah itu sendiri seperti memanen hasil tumbuhan yang hidup diatas tanah dan tidak menutup kemungkinan untuk berburu terhadap binatang yang hidup di atas tanah tersebut. Dari dulu tanah yang didiami oleh sekelompok orang sudah memiliki sistem yang jelas dimana ada yang sebagai pemimpin yang bertugas sebagai pengatur penggunaan tanah, tentunya menggunakan sistem atau sifatnya yang turun temurun dan biasa dikatakan juga sebagai warisan dari leluhurnya. Hal ini dikenal sampai sekarang dengan istilah "tanah adat" tanah adat di bali biasanya tidak dapat di pindah tangankan ke orang lain karna sistem kepemilikan menggunakan silsilah leluhur atau secara turun temurun.

Namun seiring dengan perkembangan jaman kepemilikan secara turun temurun tersebut sudah mulai di goyahkan dengan adanya sertifikat tanah yang memiliki kekuatan secara hukum dan undang-undang. Walau demikian adanya maka perlu dipertahankan "tanah adat" tersebut oleh masyarakat Hindu di Bali karna hal tersebut bersangkut paut dengan masalah agama.Setelah keluarnya UUPA, 
e-Journal Pendidikan Sosiologi Universitas Pendidikan Ganesha

Jurusan Sejarah, Sosiologi dan Perpustakaan (Volume 2, Nomor 1, Tahun 2020)

maka dalam ketentuan konversinya (pasal II, VI, VII) ditemukan hak-hak atas tanahsebagai berikut: hak agrarisch eigendom, milik, yasan andarbeni hak atas druwe, hak atas druwe desa, pesini, grant sultan, landerijen bezitsrecht, altijddurende erfpacht, hak usaha atas tanah-tanah partikelir, hak vructgebruik, gebruik, grant controleur, bruklen, ganggam bauntuik, ang gaduh, bengkok, lungguh, pituas, hak gogolan, pekulen/sanggau. Baru kemudian setelah keluarnya peraturan Menteri Pertanian dan Agraria No. 2 tahun 1962 ditambah dengan Surat Keputusan Menteri dalam Negeri No. SK26/DDA/1970 dipastikan bahwa hak-hak tanah sebagaimana diatur oleh ketentuan konversi pasal II, VI, Vii dari UUPA adalah hak-hak Indonesia atas tanah. Sebelum keluarnya UUPA yang disebut tanah-tanah adat/tanahtanah Indonesia adalah tanah-tanah yang tunduk dan diatur oleh hukum adat. Ternyata konsepsi ini masih diikuti dalam UUPA, sehingga batasan Tanah adat menurut UUPA lebih dari batasan tanah adat menurut hukum adat.

Tanah adat Bali sesuai dengan ketentuan konvensi dari UUPA tercantum dalam pasal II dengan sebutan "tanah hak atas Druwe" atau "tanah hak atas Druwe desa". Namun di Bali tanah-tanah adat lebih dikenal dengan nama "tanah druwe desa" yang artinya tanah-tanah kepunyaan desa adat. Tanah "Druwe desa" (Adi surya, Tanah Karang Desa, diakses 28 januari 2019) terdiri dari : (1). Tanah Desa yaitu tanah yang dipunyai atau dikuasi oleh Desa Adat yang bisa didapat melalui usaha-usaha pembelian ataupun usaha lainnya. Kalau tanah desa ini berupa tanah pertanian (sawah, ladang) akan digarap oleh krama desa (anggota desa) dan penggarapannya diatur dengan membagi-bagikan secara perorangan maupun secara kelompok yang kemudian hasilnya diserahkan oleh penggarap kepada desa adat. Selain itu yang termasuk tanah adalah: Tanah pasar, tanah lapang, tanah kuburan, tanah bukti (tanah-tanah yang diberikan kepada pejabat/pengurus Desa Adat selama memegang jabatan.). (2) Tanah Laba Pura, adalah tanah-tanah yang kebanyakan dulunya milik desa (dikuasai oleh desa) yang khusus dipergunakan untuk keperluan Pura. Tanah Laba Pura ini ada 2 macam yaitu Tanah yang khusus untuk tempat bangunan Pura, Tanah yang diperuntukkan guna pembiayaan keperluan Pura. (3) Tanah Pekarangan Desa atau tanah PKD adalah merupakan tanah yang dikuasai oleh desa yang diberikan kepada karma Desa untuk tempat mendirikan perumahan yang lazimnya dalam ukuran luas tertentu dan hampir sama untuk tiap keluarga. Kewajiban yang melekat ( yang lebih dikenal dengan "ayahan") pada karma Desa yang menempati tanah ialah adanya beban berupa tenaga atau materi yang diberikan kepada Desa Adat.(4) Tanah Ayahan Desa atau Tanah AYDS adalah merupakan tanahtanah yang dikuasaai atau dimiliki oleh desa yang penggarapannya diserahkan pada masing-masing Krama Desa disertai hak untuk menikmati hasil yang disertai kewajiban ayahannya.Salah satu jenis tanah adat (tanah milik desa) yang ada di Bali adalah tanah Pekarangan Desa (PKD).yaitu tanah yang dikuasai oleh Desa Adat yang diberikan kepada krama desa (warga desa) untuk tempat mendirikan perumahan yang luasnya hampir sama bagi setiap warga desa dengan melaksanakan kewajiban (ayahan) berupa tenaga atau materi kepada Desa Adat.Dalam perkembangannya terakhir ini banyak tanah milik desa khususnya tanah PKD disewakan kepada pihak lainuntuk kepentingan dibidang ekonomi dan bisnis. Adanya tuntutan ekonomi dan bisnis telah mendorong adanya praktek sewa menyewa tanah PKD oleh warga desa. (Rudi Dewa gede, jurnal notarial, 2017).

Hal demikianlah terjadi di Desa Tista Kecamatan Kabupaten Karangasem 
dimana, tanah AYDS dan tanah PKD ini di gunakan untuk kepentingan ekonomi yang pemiliknya ada beberapa menjual dan menyewakan tanah tersebut untuk kepentingan ekonomi. Namun, transaksi jual beli dan atau kontrak sewa-menyewa tanah tersebut hanya bisa dilakukan antar warga desa setempat. Dilihat dari perkembangannya hingga sekarang belum ada transaksi jual beli ataupun kesepakatan kontrak-mengontrak tanah dilakukan pihak luar dari Desa Tista. Dilihat dari desa tetangga bahwa hal tersebut diatas bisa dilakukan dengan pihak luar tentunya, hal ini menjadi sebuah bahasan yang menarik bahwa sebenarnya apa yang ingin dipertahankan oleh Desa Tista sendiri melalui pengelolaan tanah yang demikian adanya. Apakah hal tersebut merupakan strategi dari desa adat untuk menjaga warisan leluhur, ataukah hal tersebut merupakan bentuk dari ketidak sepahaman dengan pihak pemerintah yang membenarkan adanya transaksi jual beli tanah antar orang asing, dan apakah hal tersebut merupakan sebuah strategi untuk menghadapi globalisasi yang semakin meluas dan semakin memengaruhi pemikiran serta prilaku masyarakat pribumi yang mulai meninggalkan warisan leluhur yang sudah turun temurun dari nenek moyang mereka.

Penelitian mengenai Pemertahanan Desa Adat Berbasis Kontrol Sosial Terhadap Sumber Daya Tanah (Studi Kasus di Desa METODE

Di dalam proses penelitian ini, teknik pengambilan data dilakukan dengan cara triangulasi data, yang berarti dalam proses pengambilan data di kancah atau lapangan menggunakan 3 teknik, yang terdiri dari proses (1) observasi, (2) wawancara, dan (3) studi dokumen. Cara pengumpulan data dengan beragam tekniknya harus benarbenar sesuai dan tepat untuk menggali data yang diperlukan bagi kemantapan hasil
Tista, Abang, Karangasem-Bali) secara teoritis bisa ditelaah dengan teori Teori Pemertahanan Komunitas, Teori Kontrol Sosial. Dalam penelitian diformulasikan 3 (tiga) Rumusan Masalah yang terdiri dari (1) Mengapa Desa Adat Tista, Kecamatan Abang, Kabupaten Karangasem-Bali melarang jual/beli tanah pada orang luar desa? (2) Bagaimana pengelolaan sumber daya tanah di Desa Adat Tista, Kecamatan Abang, Kabupaten Karangasem-Bali? (3) Aspek-aspek apa sajakah yang bisa digunakan sebagai media pembelajaran sosiologi mengenai permasalahan tanah di Desa Adat Tista, Kecamatan Abang, Kabupaten Karangasem-Bali?

Pendekatan Penelitian ini menggunakan pendekatan kualitatif. Penelitian ini memiliki 3 (tiga) tujuan sebagai berikut: (1) Untuk mengetahui apa yang menjadi alasan Desa Adat Tista, Kecamatan Abang, Kabupaten Karangasem-Bali melakuakn jual/beli tanah kepada pihak di atau warga luar desa. (2) Untuk mengetahui bagaimana pengelolaan sumber daya tanah di Desa Adat Tista, Kecamatan Abang, Kabupaten Karangasem-Bali (3) Untuk mengetahhui aspek-aspek apa sajakah yang bisa digunakan sebagai media pembelajaran sosiologi mengenai permasalahan tanah di Desa Adat Tista, Kecamatan Abang, Kabupaten Karangasem-Bali.

penelitiannya. Ketepatan dan kemantapan data tersebut tidak hanya tergantung dari ketepatan memilih sumber data dan teknik pengumpulan datanya, tetapi juga diperlukan teknik pengembangan validitas datanya. Validitas data ini merupakan jaminan bagi kemantapan simpulan dan tafsir makna sebagai hasil penelitian. Dalam penelitian kualitatif beberapa cara yang bisa dipilih untuk pengembangan validitas 
(kesahihan) data penelitian (Sutopo, 2006:91-92). Dalam penelitian ini, untuk menjaga kesahihan data digunakan tiga macam triangulasi, yakni triangulasi sumber, triangulasi metode, dan triangulasi teori.

Dalam proses analisis data kualitatif, terdapat tiga komponen utama yang harus benar-benar dipahami oleh setiap peneliti kualitatif. Tiga komponen utama analisis tersebut adalah (a) reduksi data, (b) sajian data, dan (3) penarikan simpulan serta verifikasi Miles dan Huberman (dalam Sutopo, 2006:113). Tiga komponen tersebut berarti harus ada (dibuat/dikembangkan), HASIL DAN PEMBAHASAN

(1) Alasan Desa Adat Tista, Kecamatan Abang, Kabupaten Karangasem-Bali melarang jual/beli tanah pada orang luar desa.

Daerah Bali merupakan daerah yang sangat memegang teguh budaya leluhur, ini terbukti dari masih banyaknya tradisi-tradisi di bali yng bertahan hingga sekarang. Menurut Hendriatiningsih (2008) yang menyebutkan bahwa karakteristik desa di bali sangatlah tampak dari kehidupan agamanya yakni Agama Hindu, yang menyatu padu dengan adat beserta budaya dalam suasana harmonis dengan tidak lepas dari peran serta aparatur desa yaitu Desa Adat yang merupakan warisan prinsif jauh sebelum Indonesia merdeka.

Desa Adat Tista merupakan salah satu Desa Adat yang berada di bali yang menggunakan Hukum Adat untuk mengedalikan masyarakat yang ada di lingkup Desa Adat Tista tersebut. Meskipun secara keseluruhan tidak tertulis namun hukum adat yang telah disosialisasikan secara turun temurun ini memang sangat kuat pengaruhnya. Dalam hukum Adat Desa Tista tidak hanya mengatur tingkahlaku masyarakatnya saja tetapi juga mengatur Kepemilikan tanah yang ada didaerah tersebut. Kepemilikan tanah di dan selalu terlibat dalam proses analisis, saling berkaitan, serta menentukan arahan isi dan simpulan, baik yang bersifat sementara maupun simpulan akhir sebagai hasil analisis akhir. Tiga komponen analisis tersebut selalu dikomparasikan secara teliti bagi pemantapan pemahaman dan juga kelengkapannya. Proses interaktif secara berkelanjutan dari tiga komponen tersebut memerlukan kedisiplinan peneliti agar tidak mengalami kesulitan dalam melakukan proses analisis akhir untuk merumuskan simpulan penelitian, bilamana proses pengumpulan data sudah berakhir (Sutopo, 2006:113).

Desa Tista hanya boleh dimiliki oleh warga lokal yang merupakan warga Desa Tista itu sendiri (beragama hindu). Hal tersebut dikarenakan beragai macam faktor. Adapun faktor-faktor yang melatar belakangi hal tersebut ialah pemertahanan budaya/agama, kemajuan ekonomi masyarakat lokal, pemertahanan keajegan desa/identitas desa,

(2) Strategi Pengelolaan Sumber Daya Tanah Yang Dilakukan di Desa Adat Tista, Kecamatan Abang, Kabupaten KarangasemBali

Strategi yang digunakan dalam pengelolaan sumber daya tanah yang dilakukan di Desa Adat Tista, Kecamatan Abang, Kabupaten Karangasem-Bali melaui prooses yang amat sangat panjang. strategi yang dilakuakn adalah pada dasarnya mempertahankan kepemilikan tanah yang ada agar tetap menjadi milik olang lokal. Hal ini dimulai dengan Penetapan ayaahan desa, patokan jumlah tanah yang boleh dibeli. Surat tanah menggunakan pemohon/atas nama Desa Tista. 
e-Journal Pendidikan Sosiologi Universitas Pendidikan Ganesha

Jurusan Sejarah, Sosiologi dan Perpustakaan (Volume 2, Nomor 1, Tahun 2020)

(3) Fungsi

dan

Manfaat

Permasalahan Tanah di Desa Adat Tista, Kecamatan Abang, Kabupaten Karangasem-Bali sebagai Sumber Belajar Sosiologi di SMA

Ayahan Desa di DesaTista sebagai upaya pelestarian kearifan lokal cukup layak dijadikan sebagai sumber belajar Sosiologi di kelas XII SMA dengan KD (Kompetensi Dasar) 3.4 Memiliki pengetahuan bagaimana melakukan strategi pemberdayaan komunitas dengan mengedepankan nilai-nilai kearifan lokal di tengah-tengah pengaruh globalisasi. Salah Satu materi yang tercakup dalam KD. 3.4 adalah materi tentang kearifan lokal Ayahan Desa di DesaTista sebagai upaya pelestarian kearifan lokal bisa menjadi

\section{SIMPULAN DAN SARAN}

Alasan pemertahanan lahan yang dilakukan oleh Desa Tista salah satunya ilah untuk mempertahankan Keajegan desa/identitas desa. Pemertahanan tanah yang dilakukan oleh pihak desa agar tidak jatuh ke pihak luar akan secara langsung mempertahankan budaya-budaya yang menjadi identitas dari desa sendiri. Kegiatan masyarakat terhadap sumberdaya tanah di Desa Tista telah menjadi budaya yang dilakuakn secara turun temurun. Masyarakat desa tista memiliki sebuah kebudayaan terhadap sumberdaya tanah seperti melakukan persembahan pada saat hari Tumpek Ngatag dimana, setiap pemilik lahan menghaturkan sesaji di Pengulun karang (biasanya ujung lahan paling utara) hal ini sudah dilakukan sejak zaman nenek moyang dahulu.

Desa Tista merupakan salah satu desa yang pensertifikatan tanahnya yang telah dibeli oleh masyarakat desa dengan hak pribadi maka yang menjadi atas nama dari pemohon sertifikat bukan nama sang pembeli meliankan, atas nama Desa bahan tambahan pengetahuan bagi siswa SMA khususya kelas XII dalam pembelajaran sosiologi dalam pemahaman mengenai kearifan lokal. Untuk menunjang hal tersebut, maka perlu dilakukan identifikasi nilai-nilai karakter dalam Ayahan Desa di DesaTista sebagai upaya pelestarian kearifan lokal dan selanjutnya berusaha menyajikan informasi ringkas tentang Ayahan desa di Desa Tista dalam bentuk RPP (Rencana Pelaksanaan Pembelajaran) yang akan menunjang proses pembelajaran Sosiologi di SMA kelas XII. RPP (Rencana Pelaksanaan Pembelajaran) tersebut nantinya dapat dimanfaatkan oleh guru ketika membahas materi kearifan lokal.

Pakraman Tista. Hal ini dilakukan oleh aparat desa agar bisa tetap mengawasi kepemilikan tanah.

Ayahan Desa di DesaTista sebagai upaya pelestarian kearifan lokal cukup layak dijadikan sebagai sumber belajar Sosiologi di kelas XII SMA dengan KD (Kompetensi Dasar) 3.4 Memiliki pengetahuan bagaimana melakukan strategi pemberdayaan komunitas dengan mengedepankan nilai-nilai kearifan lokal di tengah-tengah pengaruh globalisasi. Salah Satu materi yang tercakup dalam KD. 3.4 adalah materi tentang kearifan lokal Ayahan Desa di DesaTista sebagai upaya pelestarian kearifan lokal bisa menjadi bahan tambahan pengetahuan bagi siswa SMA khususya kelas XII dalam pembelajaran sosiologi dalam pemahaman mengenai kearifan lokal. Untuk menunjang hal tersebut, maka perlu dilakukan identifikasi nilai-nilai karakter dalam Ayahan Desa di Desa Tista sebagai upaya pelestarian kearifan lokal dan selanjutnya berusaha menyajikan informasi ringkas 
tentang Ayahan desa di Desa Tista dalam bentuk RPP (Rencana Pelaksanaan Pembelajaran) yang akan menunjang proses pembelajaran Sosiologi di SMA kelas XII. RPP (Rencana Pelaksanaan Pembelajaran) tersebut nantinya dapat dimanfaatkan oleh guru ketika membahas materi kearifan lokal.

\section{DAFTAR RUJUKAN}

\section{Daftar Buku}

Mulyana, Dedy. 2004. Metodologi Penelitian Kualitatif. Bandung: PT Remaja

Rosdakarya.

Martono, Nanang. 2014. Sosiologi Perubahan Sosial Perspektif Klasik, Modern, Posmodern, dan Poskolonial. Jakarta: Rajawali Pers.

Narwoko dan Bagong. 2007. Sosiologi Teks Pengantar dan Terapan. Jakarta: Kencana

Sugiyono. 2010. Metodologi Penelitian Pendidikan. Bandung: Alfabeta.

Sudjana, Nana. 1989. Teknologi Pengajaran. Bandung: Sinar Baru.

Sugiyono. 2006. Metode Penelitian Kuantitatif Kualitatif Dengan $R$ Dan D. Bandung : Alfabetaz.

Sutopo. 2006. Metodologi Penelitian Kualitatif (Dasar Teori dan Terapannya
Kemudian saran untuk aparat Desa Tista ialah gagasan yang tengah dijalankan dapat di kembangkan sedemikian rupa dan menjadikan Desa Tista sebagai desa yang menjaga dan melestarikan kearifan lokal. Hal ini juga bisa mejadi contoh untuk desa lain dalam melestarikan budaya leluhur didalam menghadapi globalisasi

dalam penelitian). Jakarta: PT. Grasindo.

\section{Daftar Jurnal}

I Ketut Kaler. 2018. Arti dan Fungsi Tanah Adat Bagi Masyarakat Bali: Studi Kasus di Desa Adat Batubulan. DOI: 10.24843/SP.2018.v2.i01.p03. Vol.2 HIm 29-45

Komang Bagus Ida Mahaputra, dkk. 2015. Kedudukan Tanah Druwe Desa Yang Telah Diserahkan Kepada Perorangan Dalam Sistem Pertanahan Nasional. Universitas Brawijaya: 2015.

Dewa Ayu Oka Aspriani. Status Kepemilikan Tanah Druwe Desa Di Bali. Jurnal Universitas Brawijaya.

Ashari, dkk. 2012. Potensi dan Prospek Pemanfaatan Lahan Pekarangan Untuk Mendukung Ketahanan Pangan. Forum Penelitian Agro Ekonomi:2012 